\title{
Correspondence
}

http://dx.doi.org/10.11646/phytotaxa.226.2.8

\section{A type study and emended description of Haslea wawrikae (Bacillariophyta)}

\author{
FRITHJOF A.S. STERRENBURG ${ }^{1, *}$, FRIEDEL HINZ ${ }^{2} \&$ PAUL E. HARGRAVES ${ }^{3}$ \\ ${ }^{1}$ Stationsweg 158, Heiloo, the Netherlands. \\ ${ }^{2}$ Friedrich-Hustedt-Zentrum für Diatomeenforschung, Alfred-Wegener-Institut,Helmholtz-Zentrum für Polar- und Meeresforschung, Am \\ Handelshafen 12, 27570 Bremerhaven, Germany. \\ ${ }^{3}$ Affiliate Research Professor, Harbor Branch Oceanographic Institute, Florida Atlantic University and Research Associate, Smithsonian \\ Institution Marine Station, Ft. Pierce, Florida, USA. \\ *Corresponding author (E-mail: fass@wxs.nl)
}

\begin{abstract}
Type slides and the last remnant of the type sample of Haslea wawrikae were examined in LM and SEM. An emended diagnosis is presented, one new finding being that the transverse bars of the basal layer on either side of the raphe are offset - the bars on the one side aligning with the areolar foramina on the other. The species is confirmed (SEM) to have a fully developed raphe and the valve structure characterising Haslea species: an internal "grate-like" basal layer and an external tegumental layer with continuous longitudinal fissures. An erroneous identification of $H$. wawrikae was traced in the literature and the existence of similar, but non-conspecific, species is suspected.
\end{abstract}

\section{Introduction}

In Sterrenburg et al. (2015) seven new Haslea (Simonsen 1974: 46) species were presented, demonstrating that the morphological variety in the genus is much greater than the broadly generalizing descriptions in the literature-e.g. Round et al. (1990: 576), Massé et al. (2001: 625)—would suggest. It was shown that Haslea species are characterized by a sandwich-structured valve consisting of an internal grate-like basal layer and an external tegumental layer perforated by continuous longitudinal fissures. These two layers are shored by longitudinal "bulkheads" that are perforated so that they form fence-like rows (saepes) of columns. The valve contour ranges from fusiform or naviculoid to sigmoid and amphoroid. The central external raphe endings are not just simple straight fissures, they may be homolaterally or heterolaterally deflected (and sometimes either in the same species), the terminations range from well-separated to very approximate and overlapping and they may even show complex curvature with prominent teeth and pits. The internal raphe ridge is not always twisted in its more distal portions only but may also be fully tilted sideways over its entire length; conversely, it may not be appreciably tilted at all. The accessory ridge paralleling the raphe ridge may range from prominent to inconspicuous and finally, the central bars may range from prominent to absent.

Among such great variety, one species nevertheless stands out because of its extraordinary filiform valve contour: "Navicula" wawrikae Hustedt (1961: 52, fig. 1204), transferred to the genus Haslea in Simonsen (1974: 48). Hustedt (1961) writes that the raphe is rudimentary, Simonsen (1974) states that in LM a fully developed raphe can just be visualized. Transfer to the genus Haslea in Simonsen (1974) was not based on actual visualization of continuous external areolar fissures in SEM. To obtain a better insight into the morphology of the species, the last remnant of the type material was examined in SEM, which led to an emended diagnosis.

\section{Methods and materials}

Methods:-The type material had been oxidized with $\mathrm{H}_{2} \mathrm{SO}_{4}$, the slides are probably mounted in Pleurax and were examined and photographed with planachromatic objectives and DIC. Additional material was oxidized with $\mathrm{H}_{2} \mathrm{O}_{2}$. For SEM, stubs with air-dried material were sputtered with Au for examination in SEM.

Materials:-Hustedt (1961) did not designate a holotype in a slide, but marked 4 specimens in three different slides. 
On the basis of the figures in Hustedt (1961) it could not be determined which specimen present in the BRM slides was illustrated, so a lectotype (N13/22) and two isolectotype slides (N13/21, N13/23) were later designated by Simonsen. The material in BRM also included two samples: 'E11073 und E11083, Golf von Neapel, Posillipo, 10m, 12.12.1956', collected by Hustedt. Both were from the same material, E11083 had been treated with $\mathrm{H}_{2} \mathrm{SO}_{4}$ and this was used for SEM. Only a minute quantity remained. In the remainder of sample E11073, no diatoms were observed. In addition, we examined a sample from the Indian River Lagoon, Florida, USA, May $8^{\text {th }}$, 2008, in collection Hargraves, unnumbered.
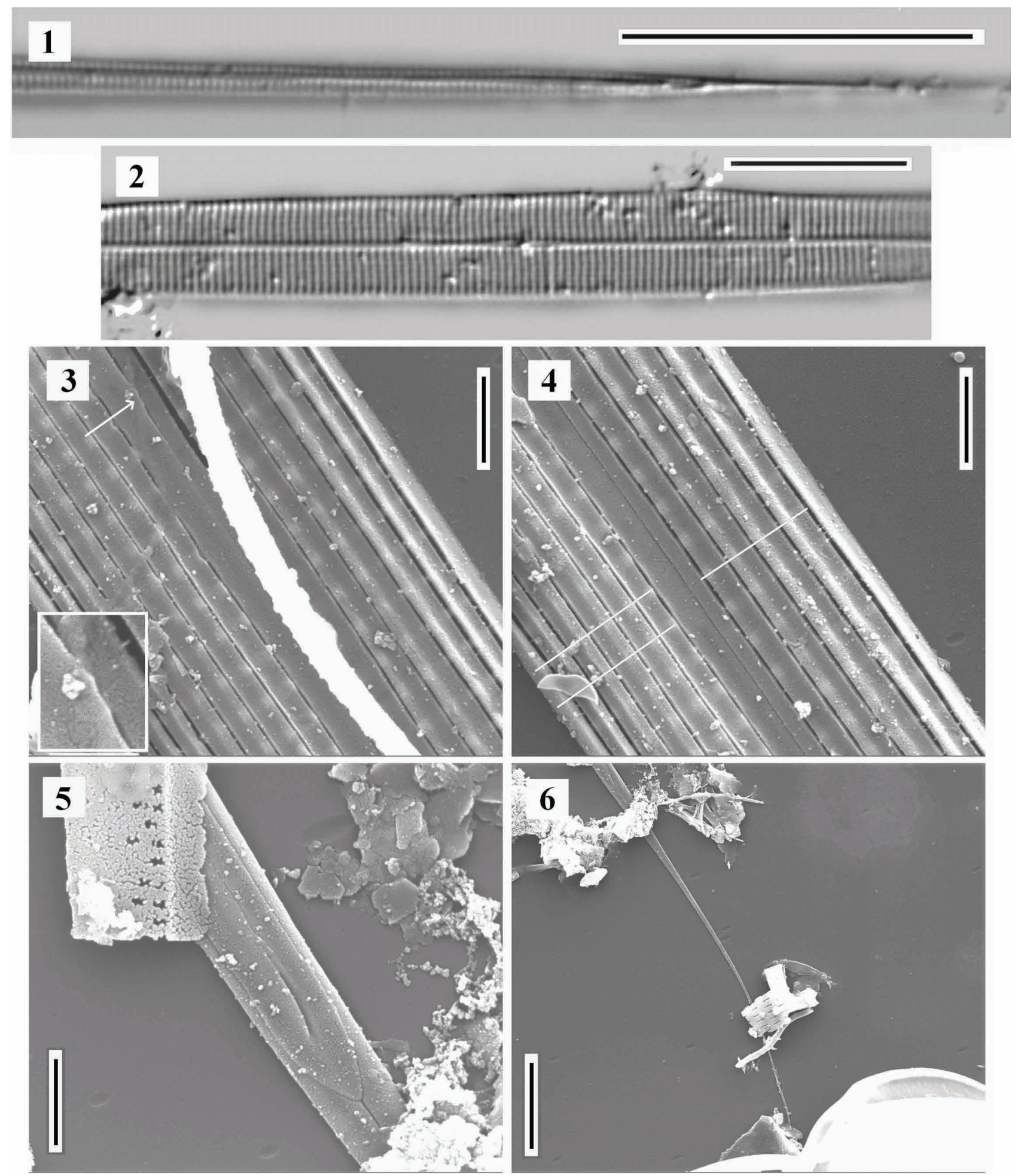

FIGURES 1-6. Haslea wawrikae, type material. 1, 2. Lectotype, LM. 1. Apex. 2. Centre. 3-6. SEM, exterior views. Centre of valve. Arrow and inset ( $2 \times$ enlargement) show central raphe fissures. 4. View about midway to apex. Lines drawn through saepes (which "shine through") mark offset striae. 5. Apex. Raphe termination slightly dilated and curved, outermost two striae fuse and end in "spur". 6. Hairlike extension of valve. Scale bars: $20 \mu \mathrm{m}$ (Fig. 1), $10 \mu$ (Fig. 2), $5 \mu \mathrm{m}$ (Fig. 6), $1 \mu \mathrm{m}$ (Figs 3-5). 


\section{Observations}

Haslea wawrikae (Hustedt) Simonsen emend. Sterrenburg \& Hinz (Figs 1-6)

Emended description of type material specimen: Valve filiform (Figs 1, 2), linear throughout with almost parallel sides (Figs 2, 4), gradually tapering towards the ends with long apical hair-like extensions (Figs 1, 6), ca. 380-560 $\mu \mathrm{m}$ long, $c a$. $4.5-6.5 \mu \mathrm{m}$ wide. Striae in perpendicular arrangement (Fig. 2), transverse $c a$. 25, longitudinal $>40$ in $10 \mu \mathrm{m}$. Striae to either side of the raphe offset, the striae on the one side aligning with the interstriae on the other (Fig. 4: offset marked with white lines). Axial and central area extremely narrow (Figs. 3, 4), no central raphe nodule visible in LM (Fig. 2). In SEM, the valve exterior shows continuous longitudinal fissures (Figs 3, 4). There is a fully developed raphe, but this is practically invisible in LM. In SEM, the external central raphe endings are extremely approximate (Fig. 3 arrow and enlarged inset), the apical raphe endings are somewhat dilated and slightly curved (Fig. 5). The two marginal fissures fuse near the apex and continue as a short straight spur (Fig. 5). The very small individual columns of the perforated saepes shoring the two layers of the valve clearly "shine through" as white spots in Figs. 3 and 4. From this, it can be inferred that the internal areolar openings of the grate-like basal layer are longitudinally elongated oblong (Figs 3,4), almost twice as long as they are wide.

Type:- Lectotype BRM N13/22, isolectotypes N13/21 and N13/23, marked specimens.
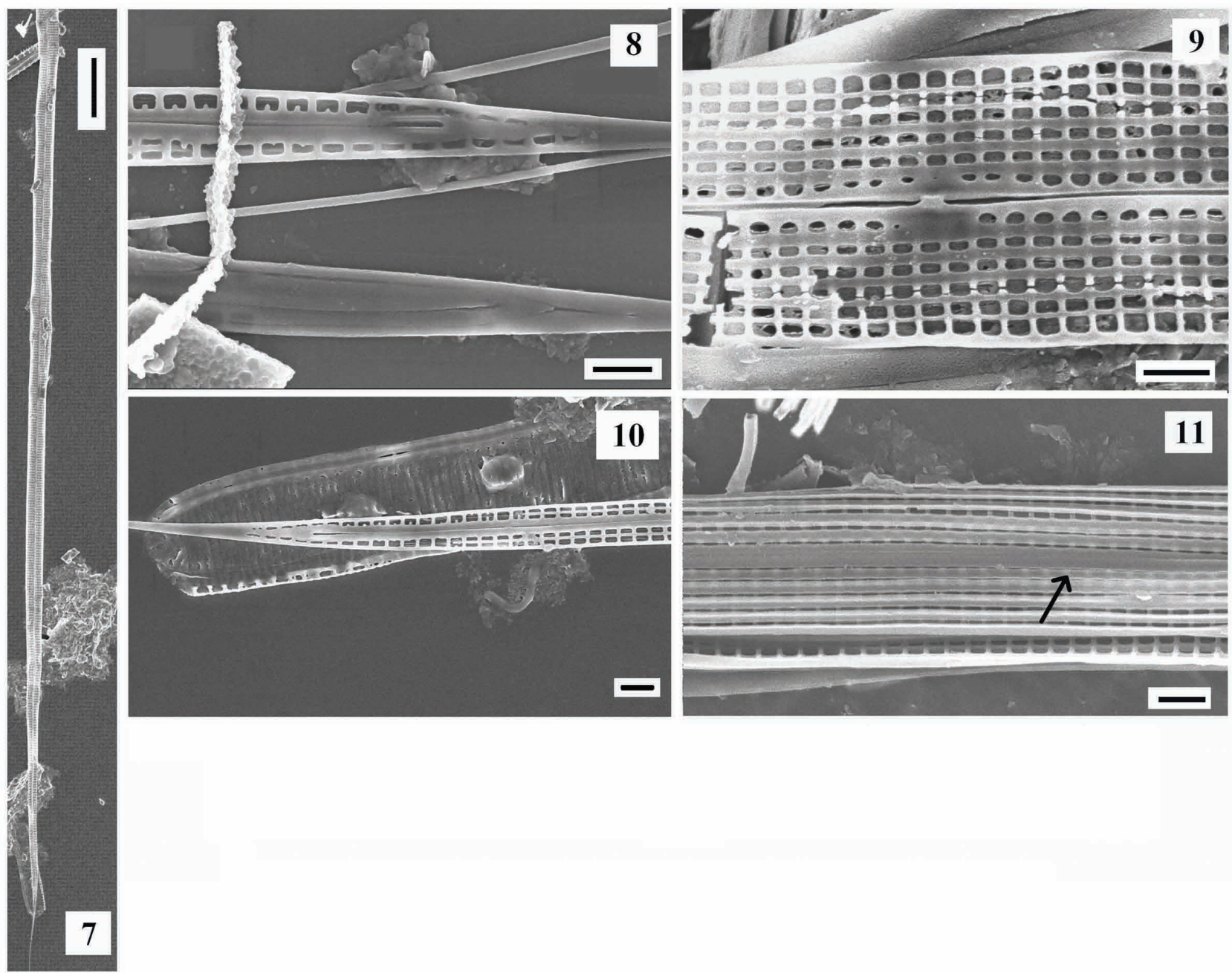

FIGURES 7-11: Haslea wawrikae, Indian River Lagoon, Florida, USA. SEM. 7. Survey. 8. Apices, interior and exterior views. Note fully developed raphe, inconspicuous helictoglossa, fused outermost longitudinal fissures ending in "spur" as in type material specimen of Fig. 5. 9. Interior view of centre. Note fully developed raphe, absence of central raphe nodule, central bars, raphe ridge and accessory ridge, and offset striae. 10. Interior view, apex. Note rudimentary raphe ridge, not sideways tilted. 11. Exterior view. Arrow marks where individual columns of saepes "shine through". Scale bars equal $1 \mu \mathrm{m}$, except Fig. $7(10 \mu \mathrm{m})$.

Observations:- The minute remnant of the type material yielded only a single valve, presenting its exterior surface. Because the columns of the saepes "shine through", the morphology of the basal layer could be inferred for the type 
material specimen (see above). This then served as a reference datum for examination of specimens in additional material that fully matched the type material specimen and also presented their interior aspect.

A sample (collection Hargraves) from the Indian River Lagoon, Florida, USA, May $8^{\text {th }} 2008$, contained filiform diatoms (Figs 7-11), which formed a perfect match of $H$. wawrikae in the type material as regards valve shape, dimensions, stria density and offset in LM and valve morphology, external central and apical raphe fissure endings, fused marginal longitudinal striae ending in a "spur" and the image of the saepes columns in SEM. Thus the conspecificity of these specimens and the type specimens is assured.

Figure 7 shows a specimen with a linear, almost parallel-sided, gradually tapering filiform valve, matching the aspect of the type. The interior views (Figs 8-10) show the internal grate-like basal layer of Haslea; through the mazes of the grate the continuous areolar fissures of the tegumental layer are seen. The exterior views of Figs 8 and 11 confirm the presence of continuous longitudinal fissures and the stria density is seen to match that of the type: striae transverse $c a .25$ in $10 \mu \mathrm{m}$, longitudinal $>40$ in $10 \mu \mathrm{m}$. The striae to either side of the raphe are offset as in the type (Fig. 9), a stria on the one side being approximately aligned with an interstria on the other. Fig. 8 shows apices of two specimens in exterior and interior view. The exterior view perfectly matches that of the type material specimen: slightly curved raphe fissure ending, the two outermost longitudinal fissures fuse and end in a "spur". The interior view shows a slightly dilated raphe fissure ending, without markedly developed helictoglossa. Figure 9 is a close-up of the centre in interior view, showing slightly dilated internal central endings of the raphe, which is seen to be fully developed in Figs 8 and 10. In confirmation of the LM findings for the type, there is no thickened central raphe nodule; SEM reveals that a central bar and accessory ridge paralleling the raphe are also absent (Fig. 9); the raphe ridge is undeveloped in both the more central portion of the valve (Fig. 9) and near the apex (Figs 8 and 10) and not sideways tilted.

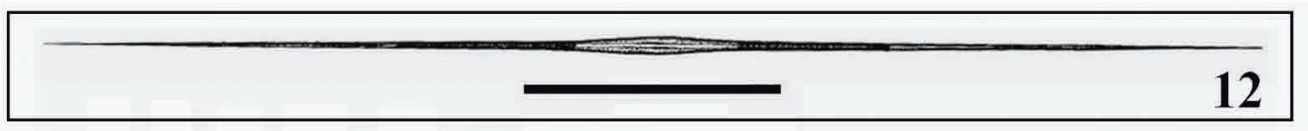

FIGURE 12: copy of drawing by Saunders \& Glenn (1969) of specimen erroneously identified as "Navicula" wawrikae. Scale bar $=100$ $\mu \mathrm{m}$.

\section{Discussion}

For Haslea wawrikae, reliable iconographic documentation (especially in SEM) has so far been lacking and the species is extraordinarily difficult to satisfactorily visualize in LM. It is easily overlooked and might even not be recognized as a diatom on routine screening of a preparation. Simonsen's (1974) transfer to Haslea was an inspired guess, proof that it belongs in that genus required SEM, however. Its valve contour is exceptional even although this is highly varied in the genus (Sterrenburg et al. 2015).

The offset of the striae on either side of the raphe ridge in Haslea was first described for H. clevei Hinz, Hargraves \& Sterrenburg in Sterrenburg et al. (2015: 152), where it was pointed out that it is also evident in H. salstonica Massé, Rincé \& Cox and H. provincialis sp. inedit. (see Gastineau et al. 2014, fig. 15.3), but was not mentioned in the texts of these publications. This offset is a significant feature determined in an early stage of valve morphogenesis, but the species involved do not appear to form a homogeneous group.

On the basis of personal observations, there are some reasons for us to suspect that there may be a "wawrikae complex": superficially similar diatoms that may or may not belong to Haslea. Although our materials are too limited to permit formal description of these suspected "pseudo-wawrikae" specimens, this caveat and a detailed description of the type may, therefore, be useful to future investigators. An example of incorrect identification was found in Saunders \& Glenn (1969: 72, 73), who discuss and illustrate a filiform diatom for which they state that it matches "Navicula" wawrikae in all respects. Actually, the specimen illustrated (reproduced as our Fig. 12) does not form a match in any respect: there is a short markedly inflated section in the middle instead of a valve that is linear with almost parallel sides gradually tapering towards the ends. The data given are: length $470 \mu \mathrm{m}$, width (centre) $5 \mu \mathrm{m}$, transverse striae 21-22 in $10 \mu \mathrm{m}$, longitudinal striae not specified. Whether this was a Haslea at all cannot be determined as no EM image was provided. 


\section{Acknowledgements}

Dr. A.K.S.K. Prasad kindly shared information on personal observations. PEH thanks Julie Piraino for SEM assistance. Two anonymous referees made helpful comments. This paper is contribution 1978 of Harbor Branch Oceanographic Institute at Florida Atlantic University, and contribution 1003 of the Smithsonian Marine Station, Fort Pierce.

\section{References}

Hustedt, F. (1961) Die Kieselalgen Deutschlands, Österreichs und der Schweiz. Dr. L. Rabenhorsts Kryptogamenflora von Deutschland, Österreich und der Schweiz 7 (3): 1-160.

Gastineau, R., Davidovich, N., Hansen, G., Rines, J., Wulff, A., Kaczmarska, I., Ehrman, J., Hermann, D., Maumus, J., Hardivillier, Y., Leignel, V., Jacquette, B., Meleder, V., Hallegraeff, G., Yallop, M., Perkins, R., Cadoret, J.P., Saint-Jean, B., Carrier, G. \& Mouget, J.L. (2014) Haslea ostrearia-like diatoms: biodiversity out of the blue. Advances in Botanical Research 71: 441-446. http://dx.doi.org/10.1016/b978-0-12-408062-1.00015-9

Massé, G., Rincé, Y., Cox, E.J., Allard, G., Belt, S.T. \& Rowland, S. (2001) Haslea salstonica sp. nov. and Haslea pseudostrearia sp. nov. (Bacillariophyta), two new epibenthic diatoms from the Kingsbridge estuary, United Kingdom. Comptes rendus de l'Académie des sciences. Série III, Sciences de la vie 324: 617-626.

http://dx.doi.org/10.1016/S0764-4469(01)01330-0

Round, F.E., Crawford, R.M. \& Mann, D.G. (1990) The diatoms. Biology and morphology of the genera. Cambridge University Press, Cambridge, 747 pp.

Saunders, R.P. \& Glenn, D.A. (1969) Diatoms. Memoirs of the Hourglass Cruises 1 (3): 1-119.

Simonsen, R. (1974) The diatom plankton of the Indian Ocean Expedition of RV “Meteor" 1964-1965. "Meteor" Forschungsergebnisse, Reihe D19: 1-107.

Sterrenburg, F.A.S., Tiffany, M.A., Hinz, F., Herwig, W.E. \& Hargraves, P.A. (2015) Seven new species expand the morphological spectrum of Haslea. A comparison with Gyrosigma and Pleurosigma (Bacillariophyta). Phytotaxa 207 (2): 143-162.

http://dx.doi.org/10.11646/phytotaxa.207.2.1 